\title{
Evolution of techniques for aesthetic penile enlargement during prosthesis placement: a chronicle of the Egydio non-grafting strategy
}

\author{
Steven K. Wilson $\left(^{1} \cdot\right.$ Lexiaochuan Wen $\left(^{2} \cdot\right.$ Paulo H. Egydio ${ }^{3}$
}

Received: 5 September 2020 / Revised: 27 September 2020 / Accepted: 10 November 2020

(c) The Author(s), under exclusive licence to Springer Nature Limited 2020

\begin{abstract}
Since penile prostheses only provide axial rigidity, correction of penile deformity and enlargement of the visible penis during implant surgery may be desired. Evolving techniques of tunica expansion have made it possible to avoid grafting and preservation of the cylindrical appearance without bulges and indentations. After two decades of devising individualized solutions for patients and continuous enhancements of existing surgical solutions, Dr. Paulo Egydio has arrived at his Tunica Expansion Procedure (TEP). This strategy is his newest iteration of a lengthening techniques without grafting accompanied by penile prosthesis implantation. The TEP Strategy permits surgeons to use their own intuitive reasoning to determine the best pattern of multiple, small, staggered incisions to promote length and girth enlargement.
\end{abstract}

\section{Introduction}

Erectile Dysfunction (ED) is often associated with reduction of visible penile size, both in length and girth [1]. This is a common phenomenon for men who have experienced fibrosis from many conditions, including Peyronie's disease (PD), diabetes, pelvic surgery, radical prostatectomy, pelvic radiotherapy, or even aging itself [2-6]. Patients may also lose adequate axial rigidity with no solution available from oral medications or intracavernous penile injections. This workshop is the product of a long interview with a trail blazing urologist, Paulo Egydio. Since completing his training 25 years ago, Paulo has been unique in the world by limiting his practice to functional reconstruction, maximum restoration of size, and the best possible aesthetic result.

Steven K. Wilson

skwilson@mac.com

$\triangle$ Lexiaochuan Wen

Wen.lexiaochuan@mayo.edu

$\triangle$ Paulo H. Egydio

phegydio@me.com

1 Institute for Urologic Excellence, La Quinta, Indio, CA, USA

2 Mayo Clinic, Rochester, MN, USA

3 Egydio Medical Center, São Paulo, Brazil

\section{Historical perspective}

Dr. Paulo Egydio obtained a bachelor's degree in Medicine in Brazil (1984-1990) and received his master's degree in General Surgery from the University of Sao Paulo (USP), Brazil (1991-1992). During rotation at USP, Paulo spent one month in the burn unit where meshing and skin grafts were applied to expand tissues. Paulo noticed that grafts were expandable up to four times the original size; this was an important clue to his future career. While in Urology Residency (1993-1996), he participated in informal fellowships in the United States-general Urology at the Mayo Clinic School of Medicine in Jacksonville, Florida and Sexual Medicine at the Cleveland Clinic Foundation, Center of Sexual Function, in Cleveland, Ohio.

Paulo drew inspiration for future research during residency when he observed patients with small penis and crooked deformities, especially PD. It became clear to him that many of these afflicted patients who underwent surgery, with or without penile prosthesis implantation, had not anticipated that their loss of penile length would be worsened by the surgery.

In 1998, Paulo began practicing medicine in the public sector with a research focus on the surgical treatment of PD at USP. From the beginning, he dedicated himself to discover innovative techniques to restore length for patients who had suffered penile shortening from disease or who simply had penile dysmorphia—perceived short penis. In 
2000, he completed his $\mathrm{PhD}$ dissertation, "Correction of Penile Deformities caused by Peyronie's Disease using an Incomplete Circumferential Incision with a Double-Y and a Bovine Pericardial Graft" at USP [7]. This technique was based on geometric principles to elongate the short side of curved penile shafts [7-14].

After completion of his $\mathrm{PhD}$, Paulo enlisted in a private clinic but still engaged in clinical research at USP until 2006. In 2003, he founded his own private clinic focusing on treatment of PD, implantation of penile prosthesis, correction of penile deformities, and enhancement of the size of the visible penis.

To Wilson's knowledge, Egydio limiting his practice to penile aesthetics and correction of deformities was a first in the world. As such, other urologists were keen to hear him lecture and watch him perform surgery. For more than 20 years, Egydio has participated in workshops, conferences, and lectures on five continents. He has performed live surgery as well in many different countries. Notably, from the beginning, he maintained a data bank of every surgery performed at home and abroad. This allowed him to easily track the number of cases and quantitate outcomes for each iteration of functional and aesthetic penile surgery he himself developed.

Paulo's availability for lectures and surgical workshops (frequently at his own expense) and his published clinical research, in effect, marketed his surgical prowess to both physicians and patients. As a result, patients travel from all over the world to seek treatment at his private practice. Paulo recently received recognition at the most recent American Urological Association (AUA) meetings, a testament to a growing acceptance of a niche urologic practice which he has spearheaded. He took first place at a Survivor Debate in a plenary session of the 2019 AUA [15] and Best Poster for the 2020 virtual AUA [16, 17].

\section{Caveats for penile enhancement}

Many patients do not know the extent to which their penises have diminished in size because they are unable to have full erections. A pharmacologically induced erection and stretched penile length measurement must be performed prior to engaging the patient in a frank discussion of what is realistic to expect from his surgery. While the clinical evaluation serves to educate the patient's perspective of his prospective penile surgery, full potential length can only truly be determined after the neurovascular bundle (NVB) has been elevated [12, 18-21].

In a similar vein, the largest possible implant size cannot be determined until maximum intraoperative penile length has been achieved. Placement of a prosthesis in an environment of penile fibrosis without reconstruction will result in straightening and improved axial rigidity but is not associated with enlargement. Regardless of patient preference, the choice of malleable or inflatable penile prosthesis (IPP) must be based on the patient's anatomy and manual dexterity. Consequently, the surgeon must educate the patient regarding the type of implant more likely to result in better axial rigidity and maximum length gain.

The basic premise of tunica albuginea reconstruction is to maximize the relationship between the volume of the penile shaft and its ability to contain the largest cylinder possible. The larger the shaft of the penis, the greater the capacity of the cylinders, both in length and girth. Intraoperative tunica adjustment allows surgeons to achieve maximization of both.

\section{Evolution of techniques for penile enhancement}

Until the recent introduction of the Egydio Tunica Expansion Procedure (TEP), five evolving surgical technique developments had previously occurred. During this advancement, Egydio performed all of these procedures. The five techniques are illustrated in Fig. 1 and the years given for each indicate the time line when Paulo dedicated to each technique.

\section{Geometrical technique [7-14] 2000-2004 (Fig. 1a)}

This procedure places a single relaxing incision with grafting to straighten the penis by restoring the short side to the same size as the long side. The equalization of both sides provides straightening but does not restore maximum potential penile length. Paulo performed the Geometrical Technique in 122 patients using bovine pericardial grafts with only 6 receiving penile prosthesis. The mean increase in functional penile length for PD with no prosthesis was $2.9 \mathrm{~cm}$, and for PD with prosthesis $2.8 \mathrm{~cm}$.

The disadvantages of this approach is the creation of large defects on the tunica which necessitate grafting:

- Surgeons have difficulty matching the size of available grafting with the area of large defects on the tunica albuginea.

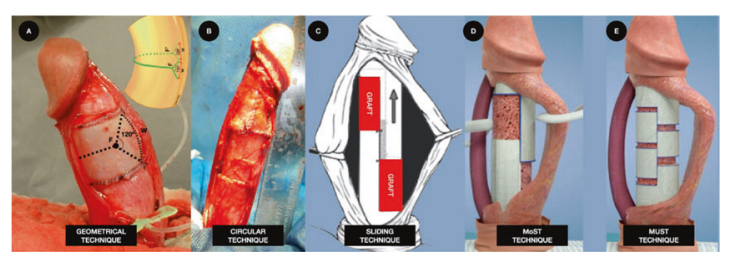

Fig. 1 Evolution of expansion. a Geometrical technique. b Circular and longitudinal incision Technique. c Sliding technique. d MoST technique. e MUST technique. 
- Grafting tissues vary in thickness, as does the tunica albuginea of each patient, which may create indentations if improperly matched.

- The likelihood of bulging after repair of large defects increases in proportion to inconsistencies in the resistance of the grafting tissues.

- Since grafts are avascular tissues, retraction may occur during the healing process.

More importantly, the length originally lost from PD is not regained, and, if prosthesis is not used, the durability of length gained intraoperatively is suspect.

Egydio refined the Geometric Technique based on experiences shared with Dr. Sava Perovic in Serbia. During five annual visits to Belgrade to perform live surgery, Paulo became even more inspired to develop a new technique that would permit maximum elongation of both sides of the penis while possibly eliminating the need for grafting [22].

\section{Circular and longitudinal incision technique [12, 18-21] 2006-2011 (Fig. 1b)}

Egydio addressed the deficiencies of the Geometrical Technique with two improvements: (1) extending the transverse incision to correspond to the circular incision around the tunica albuginea until both sides of the penis were straightened and enlarged to the limit of the mobilized urethra and NVB, and (2) longitudinal incisions to treat shaft narrowing. Grafting was still required to cover the large gaps in the tunica albuginea so there was a continuing risk of bulging and indentations on the penile shaft.

Paulo used this technique in 105 surgeries with grafting and concomitant prosthesis. The main advantage of this approach is improved lengthening of the penile shaft, with a mean functional length gain of $3.6 \mathrm{~cm}(2-5 \mathrm{~cm})$ and high patient satisfaction of $95 \%$.

\section{The sliding technique [23, 24] 2012 (Fig. 1c)}

Dr. Luigi Rolle and his group from Turin University devised the Sliding Technique, an evolution of the Circular Incision Technique, to maintain greater tunica strength and allow lengthening of each side by dividing one defect into two, dorsal and ventral, with grafting, as well as extensive NVB and urethral dissection. The multicentric study reported the technique performed from June 2010 to January 2014 in 28 patients, all with grafts and concomitant prosthesis.

\section{The modified sliding technique (MoST) $[25,26]$ 2013-2014 (Fig. 1d)}

The concept of splitting a larger defect into two smaller ones moved Egydio towards elimination of grafting altogether. While retaining the essential elements of the Sliding Technique, he made two key modifications: (1) utilization of complementary longitudinal ventral and/or dorsal tunica incisions for girth restoration, and (2) avoidance of grafts by covering of the tunica defects with Buck's fascia only. The MoST technique eliminated grafts, saved time, decreased infection risk and cost of surgery. Paulo performed this procedure on 143 patients (133 malleable, and 10 IPP) with an average length gain of $3.1 \mathrm{~cm}$.

Unfortunately, during performance of both the Sliding Technique and its modification, the MoST technique, surgeons began to note a very rare complication of prosthesis surgery-glans ischemia and subsequent glans necrosis. In 2017, a seminal publication gathered 21 instances of the devastating condition from 8 centers in 5 countries. In this report, $33 \%$ of patients underwent some form of Sliding Technique. Analysis of the risk factors for development of glans ischemia were thought to be among the following:

1. Comorbid conditions including radiation, smoking, diabetes, previous implant removals, and vascular insufficiency.

2. Employment of the subcoronal incision for surgical exposure and use of constrictive penile wrap as a dressing with indwelling catheter.

3. The Sliding Procedure or MoST modification for penile enhancement.

4. Urethral compromise by extensive dissection and/or iatrogenic injury [27].

\section{The MUST technique $[28,29]$ 2013-2016 (Fig. 1e)}

By introducing the Multiple Slit Technique (MUST), Egydio continued the important principle of graft avoidance, but, instead of two large defects, he distributed the expansion of tunica tissues among multiple, small incisions throughout the shaft of the penis. Horizontal slits lengthened the shaft, and vertical slits eliminated tunica constriction such as hourglass deformity. Egydio performed MUST in 138 patients with every patient receiving a penile prosthesis (103 malleable and 35 IPP). Penile length gain was a mean of $3.1 \mathrm{~cm}$. The advantage is maintenance of tunica strength without grafting, but indentations may still occur. Even though urethral dissection is minimized, one patient still sustained glans ischemia.

\section{Egydio's tunica expansion procedure (TEP) [15, 17, 30-32] 2016-present (Fig. 2)}

Simply stated, the TEP Strategy is nothing more than a series of multiple, small, staggered cuts positioned on the 


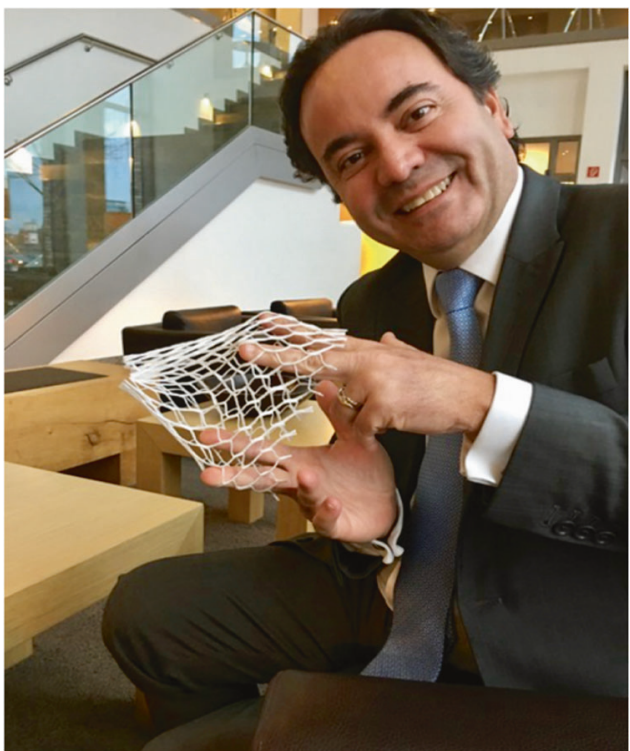

Fig. 2 Paulo is a dedicated oenophile. One day his attention was drawn to the protective mesh on a wine bottle purchased in Airport Duty Free. While testing the stretch limits, he noticed that the geometrical shapes of the spaces could be changed by expanding the mesh. These observations ultimately led Paulo to craft a mesh-like environment for tunica albuginea expansion.

tunica albuginea in a meshed pattern [33] based on the relationship of the two most important objectives: preservation of tunica strength and maximization of length and width expansion (Fig. 3).

Important TEP considerations:

- The concept does not work without simultaneous prosthesis placement.

- TEP Strategy does not affect strength of the tunica albuginea.

- The healing process rapidly obliterates the tiny slits, so no grafts are necessary.

- The ideal length of the cuts is between 5 and $8 \mathrm{~mm}$ in length, and the ideal distance separating the cuts is between 2 and $3 \mathrm{~mm}$.

- The defects are made to the maximum depth of the entire tunica or scar tissue without the need to penetrate the cavernous tissue beneath.

- The limit of penile lengthening should be determined after dissection of the NVB and placement of incisions on the tunica albuginea have been performed to relax and expand the shaft. Notably, the urethra is not dissected and left untouched.

- Only after lengthening may maximum cylinder size be determined.

- Non-expandable areas of the penis are not removed, even in case of calcifications, because incisions and expansions can occur in adjacent tissues (Fig. 4).

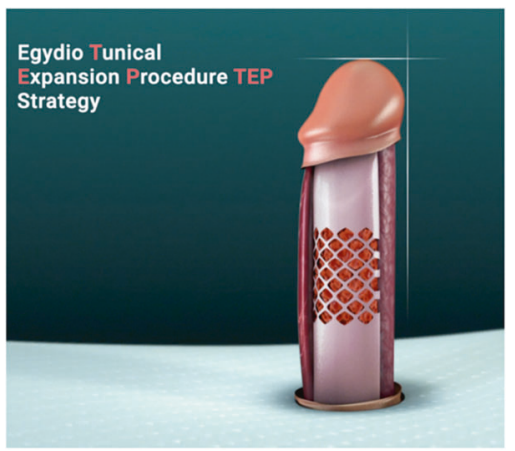

Fig. 3 The Egydio TEP strategy. Similar to the mesh protective covering on a wine bottle, the TEP allows expansion of the tunica.

A firm principle of the TEP Strategy is that vertical and horizontal incisions cannot be combined in one place on the penile shaft. The direction of the incisions must be the same in a particular area because cross-meshing is associated with loss of tunica strength [34].

When rear tip extenders (RTEs) are utilized to achieve the correct cylinder length, they may diminish axial rigidity [35]. Egydio advises placement of the inflatable portion of the cylinders directly inside the proximal corpora and minimal use of RTEs to obtain better column strength.

\section{Surgical technique}

Egydio uses a 2.5 Loupes magnification for safer NVB dissection to minimize risk of neural and vascular damage and applies a no-touch technique [36, 37] with a subcoronal incision and degloving $[8,9]$ to provide excellent exposure of the penile shaft for application of the TEP Strategy. The reservoir of a 3-piece prosthesis is inserted early on during the procedure with the bladder empty to eliminate the need for a urethral catheter. Longitudinal, paraurethral incisions are made on the Buck's fascia followed by dissection of the proximal NVB. The glans is twisted down, and the distal bundle is everted by rolling it back (Fig. 5).

After the NVB has been extensively freed from the surface of the tunica, the TEP Strategy is used to expand the tissues of the tunica albuginea (Fig. 6).

The selection of cylinder size can only be made after enlargement of the tunica albuginea by the multiple slits. For malleable cylinders, proximal and distal detachment of the cavernous spongy tissues from the tunica albuginea create a tunnel-like space for placement of the cylinders and minimization of damage to the cavernous tissue $[38,39]$. To prevent ventral or lateral migration of both, whether IPP or malleable, the cylinders are anchored to the distal extremities of the tunica (Fig. 7). 


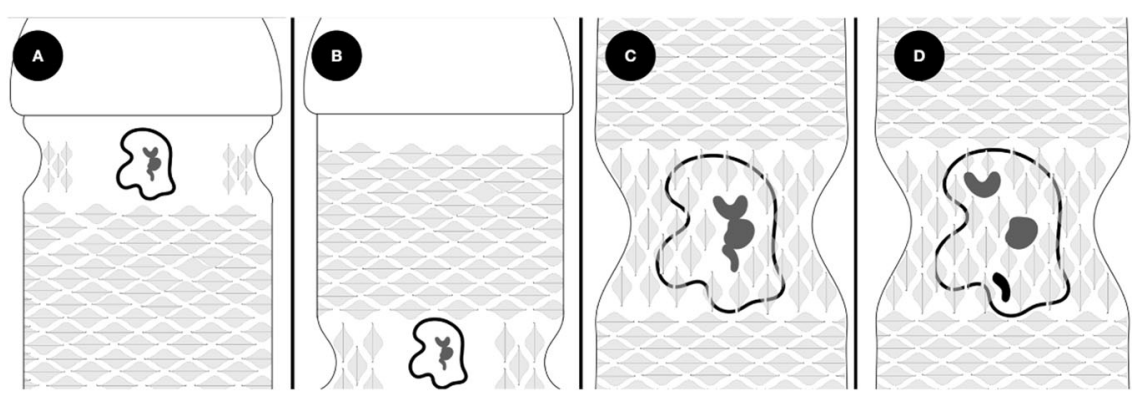

Fig. 4 Scars and calcifications do not need to be removed with the TEP. a Correction of calcified plaque causing hourglass deformity. b The same but in the mid-shaft. c A larger plaque expanded with incisions adjacent to the calcification. d Multiple calcifications on a larger plaque with a tunica relaxing incision around the calcifications.

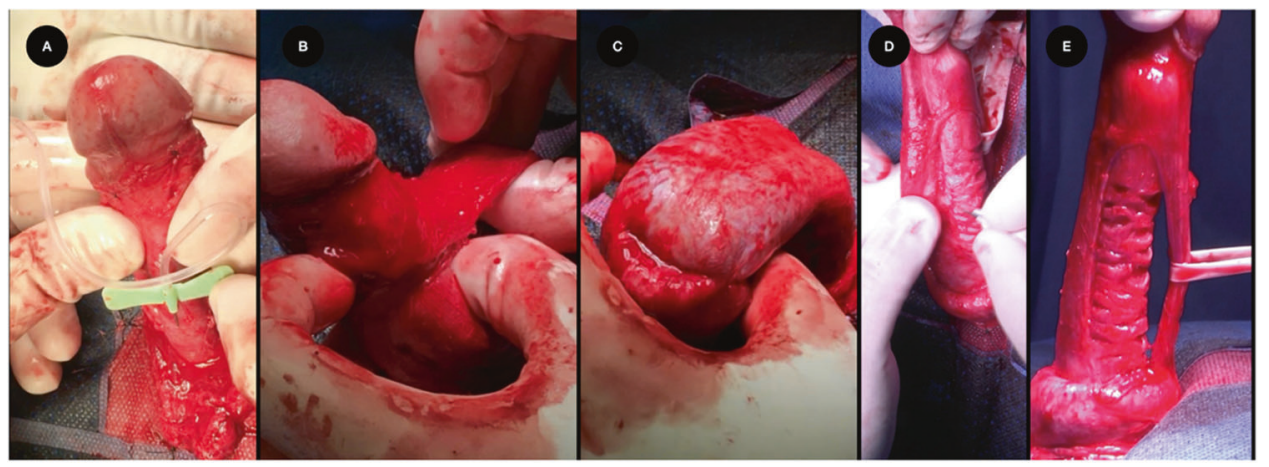

Fig. 5 Intraoperative TEP. a 23-gauge needle injects vasoactive solution to promote intraoperative vasodilation of glans. $\mathbf{b}$ Dissection of NVB beginning with paraurethral incisions. c Glans eversion permits distal dissection of the NVB for tissue expansion \& distal cylinder

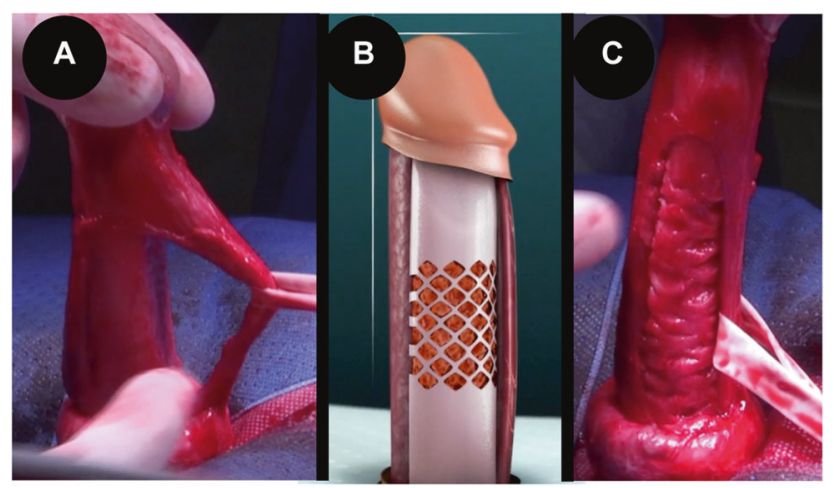

Fig. 6 TEP length gain. a The dissected NVB indicates potential lengthening of the visible penis. b Diagram of TEP strategy: the stretched cuts became squares with maximum expansion at the center of the incisions. c Multiple horizontal incisions permitted tissue expansion to increase length to the limits of the undissected urethra and the mobilized NVB.

The penis must be evaluated in full using intraoperative artificial erection prior to interruption of tunica integrity with the TEP to determine if narrowing and/or shortening are present. anchorage. d Urethra undisturbed: length gained by dissection of NVB only. e Stretched penile length verifies length restoration limited only by the NVB.

Reconstruction must occur in two separate stages to avoid compromising tunica strength with cross-mesh [34] (Fig. 8a). Vertical and horizontal cuts must be made independently in each stage. In the first stage, only vertical cuts may be used to correct narrowing, indentations, and hourglass deformity. In the second stage, only horizontal cuts may be used to treat shortening by elongation of the penis but only in areas adjacent to the cuts made in stage one (Fig. 8b).

\section{Experience with the TEP}

From February 2016 to February 2019, 416 patients who had not previously experienced penile surgery underwent penile correction and implantation with the Egydio TEP Strategy. All the patients had therapy resistant impotence, and $68 \%$ had deformity from PD; all were dissatisfied with penile length. Patients had preoperative evaluation with an injection with vasoactive drug and a color Doppler to assess penile shape and function. Patients were surveyed with International Index of Erectile Function (IIEF) [40] and the 


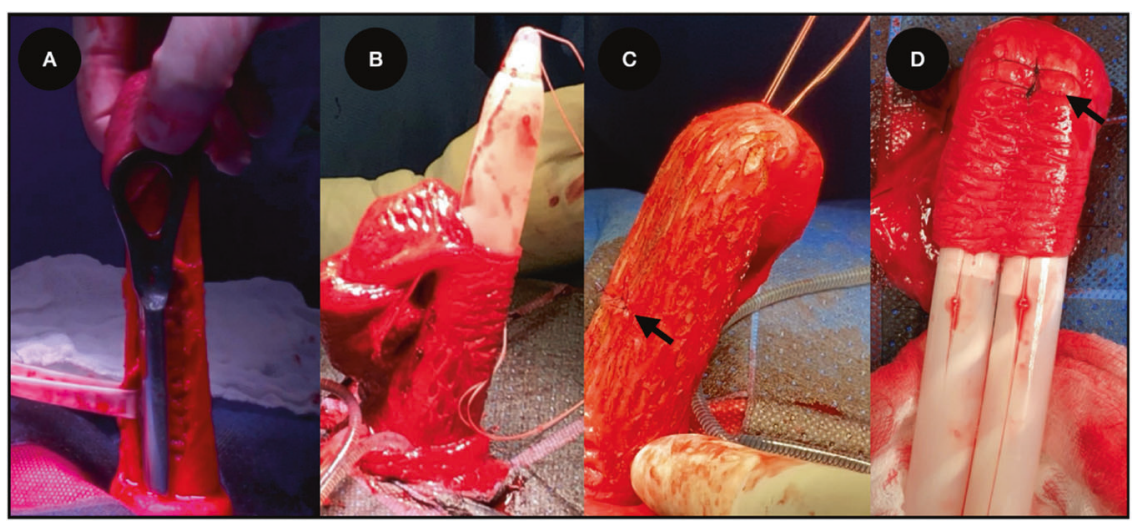

Fig. 7 Stabilization of cylinders. a After dissection of NVB, measurement to use the largest possible cylinders and the smallest possible rear tip extenders. b For IPP cylinders, the glans is everted to permit maximum distal dissection of the NVB where incisions are made for tissue expansion. IPP cylinders are first exteriorized by a second midshaft corporotomy. c The cylinders are inserted into the distal corpora where they will be stabilized by two guide strings exiting the distal corpora. 2nd corporotomy closed. (arrow). d For malleable cylinders, the dorsal tips are secured with permanent 000 sutures (arrow) to avoid device displacement.

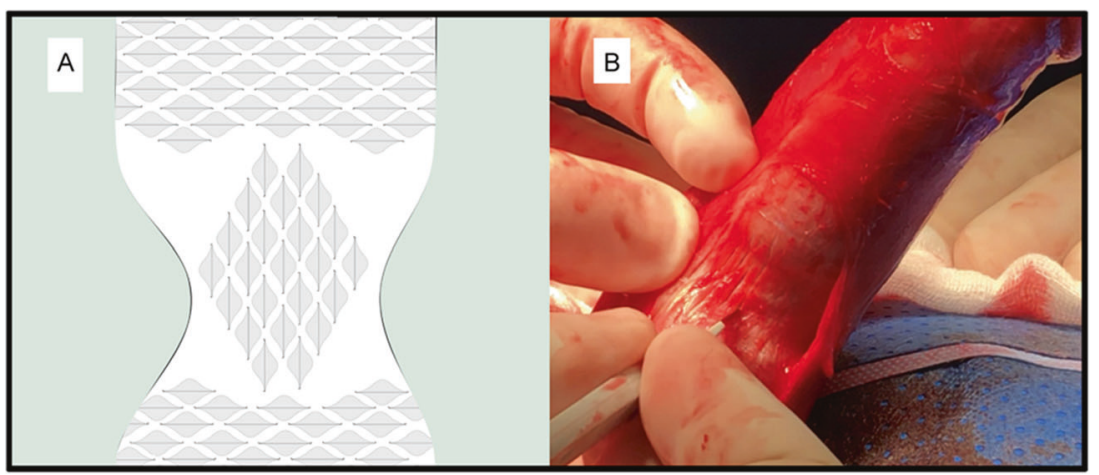

Fig. 8 Avoidance of cross meshing. a Diagram of vertical incisions for corrections of indentations and hour-glass deformity in separate locations from horizontal cuts. b Horizontal incisions on the penile

Erectile Dysfunction Inventory of Treatment Satisfaction (EDITS) [41] 6 months before and after the surgery.

The operative time was $1.5 \mathrm{~h}$ for malleable and $2 \mathrm{~h}$ for inflatable prostheses. Penile gain was $3.3 \mathrm{~cm}(2-6)$. All patients had curvature correction. Glanspexy for stabilization of the cylinder tips was performed in $93 \%$ cases. Temporary glans numbness occurred in $4 \%$ and anorgasmia in 7\%; both conditions had resolved in 6 months. Mean follow-up time was 12 months (6-36). Hematoma occurrence was $20 \%$ but did not require drainage, and prosthesis infection was $0.24 \%$ (1). No case of glans necrosis occurred.

The TEP Strategy [15-17, 30-32] is the next generation of the MUST $[28,29]-a$ lengthening technique without the necessity of grafting which eliminates large tunica defects by substituting patterns of small, staggered incisions. TEP improves tissue expansion while maintaining structural integrity. The smaller defects facilitate tissue regeneration shaft for lengthening must be made in other areas than where vertical incisions have not been performed. This avoids cross mesh which would result in bulging and insufficient support for the cylinders.

$[42,43]$. Surgical objectives may be achieved regardless of the type of implant used because optimum axial rigidity is obtained. Patients who are concerned about the cost of IPP but are worried about visibility of malleable implants should be advised that the use of tight underwear along with improved penile malleability six months after surgery is adequate for most patients to adapt to life with a malleable prosthesis.

\section{Conclusion}

Paulo Egydio has been pursuing surgical triumph for miserable patients afflicted with crooked or short penises for over two decades. In the maturation of his quest to lengthen the visible penis, he has endured challenges severe enough to cause most of us to abandon the dream and return to safer avenues of Urology. Except for the necessity of elevation of 
the NVB, his latest procedure seems relatively simple and safe. Certainly, the principles of multiple tiny relaxing incisions without grafting seems sound, and his single surgeon, large series quoted above gives confidence that the outcomes are satisfactory. Concomitant implant of a prosthesis is a necessity to assure durability of the length gain. Elimination of grafting and urethral dissection provides safety from the worst complications of flail penis and glans necrosis. Perhaps it is time for mainstream prosthetic urology to consider adopting the TEP principles of expansion of the tunica into our practice for those patients who advise us to "make it as long as you can, Doc" [44].

To paraphrase Sir Winston Churchill,

\begin{abstract}
"This is not the end. It is not even the beginning of the end. But it is, perhaps, the end of the beginning of penile aesthetic surgery's entrance into the realm of everyday prosthetic urology."
\end{abstract}

\section{Compliance with ethical standards}

Conflict of interest SKW: Consultant for AMT, Coloplast, International Medical Devices. Lecturer for Boston Scientific. Stockholder NeoTract. LW: None. PHE: None.

Publisher's note Springer Nature remains neutral with regard to jurisdictional claims in published maps and institutional affiliations.

\section{References}

1. Carvalheira A, Santana R, Pereira NM. Why are men satisfied or dissatisfied with penile implants? A mixed method study on satisfaction with penile prosthesis implantation. J Sex Med. 2015;12:2474-80.

2. Vasconcelos JS, Figueiredo RT, Nascimento FL, Damião R, da Silva EA. The natural history of penile length after radical prostatectomy: a long-term prospective study. Urology. 2012;80:1293-6.

3. Park KK, Lee SH, Chung BH. The effects of long-term androgen deprivation therapy on penile length in patients with prostate cancer: a single-center, prospective, open-label, observational study. J Sex Med. 2011;8:3214-9.

4. Otero JR, Cruz CR, Gómez BG, Geli JS, Polo JM, Castañé ER, et al. Comparison of the patient and partner satisfaction with 700CX and Titan penile prostheses. Asian J Androl. 2017;19:321-5.

5. Levine LA, Benson J, Hoover C. Inflatable penile prosthesis placement in men with Peyronie's disease and drug-resistant erectile dysfunction: A single-center study. J Sex Med. 2010;7:3775-83.

6. Kueronya V, Miernik A, Stupar S, Kojovic V, Hatzichristodoulou $\mathrm{G}$, Egydio PH, et al. International multicentre psychometric evaluation of patient-reported outcome data for the treatment of Peyronie's disease. BJU Int. 2015;115:822-8.

7. Egydio PH. Correção da deformidade peniana na doença de Peyronie's com incisão circunferencial incompleta em duplo Y na placa e enxerto de pericárdio bovino. Doctoral dissertation, Publication $N^{\circ}$ USP/FM/SBD-257/00. São Paulo, Brazil: University of São Paulo Medical School; 2000.

8. Egydio PH, Lucon AM, Arap S. Treatment of Peyronie's disease by incomplete circumferential incision of the tunica albuginea and plaque with bovine pericardium graft. Urology. 2002;59:570-4.

9. Egydio PH, Lucon AM, Arap S. A single relaxing incision to correct different types of penile curvature: surgical technique based on geometrical principles. BJU Int. 2004;94:1147-57.

10. Egydio PH. Surgical Straightening With Tunica Incision and Grafting Technique. In: Levine Laurence A (ed). Peyronie's disease: a guide to clinical management. Totowa, NJ: Humana Press Inc.; 2007. p. 227-39.

11. Egydio PH, Deformidade Peniana Adquirida (Doença de Peyronie). Joaquim José Gama-Rodrigues, Marcel Cerqueira Cesar Machado, Samir Rasslan (ed). Clínica Cirúrgica - Medicina USP. Barueri, SP, Brasil: Editora Manole Ltda.; 2008. pp. 1323-9.

12. Egydio PH, Austoni E. Geometric plaque surgery. In: Austoni E (ed). Atlas of reconstructive penile surgery. Pisa, Italy: Pacini Editore SpA; 2010. pp. 309-21.

13. Sansalone S, Garaffa G, Djinovic R, Pecoraro S, Silvani M, Barbagli G, et al. Long-term results of the surgical treatment of Peyronie's disease with Egydio's technique: a European multicentre study. Asian J Androl. 2011;13:842-5.

14. Konstantinidis K, Kuehhas F, Papatsoris A. The Egydio geometrical procedure for managing penile curvature using a single relaxing incision: A single-centre experience with 330 patients. Arab J Urol. 2015;13:287-90.

15. American Urological Association. Survivor Debate: IPP with degloving preferred treatment in difficult case of penile shortening, deformity, media release. 2019. https://www.auadailynews. org/survivor-debate-ipp-with-degloving-preferred-treatment-indifficult-case-of-penile-shortening-deformity/. Accessed 12 Aug 2020.

16. American Urological Association. Best Poster Winners - PDF. 2020. https://www.auavirtual.org/2020\%20Virtual\%20Science\% 20-\%20Best $\% 20$ Poster\%20Winners\%20-\%20PDF.pdf. Accessed 12 Aug 2020.

17. Egydio PH, MP39: Sexual function/dysfunction: surgical therapy II, MP39-04: an innovative strategy for non-grafting penile enlargement: The Egydio paradigm for tunica expansion procedures (TEP), moderated poster AUA 2020. https://www. eventscribe.com/2020/AUA2020/fsPopup.asp?Mode= presInfo\&PresentationID $=722225$.

18. Egydio PH. Surgical treatment of Peyronie's disease: choosing the best approach to improve patient satisfaction. Asian J Androl. 2008;10:158-66.

19. Egydio PH, Perovic SV, Sansalone S. Surgical Treatment of severe Peyronie's Disease for maximum penile length and girth gain. J Urol. 2008;179:256.

20. Sansalone S, Garaffa G, Djinovic R, Egydio P, Vespasiani G, Miano R, et al. Simultaneous penile lengthening and penile prosthesis implantation in patients with Peyronie's disease, refractory erectile dysfunction, and severe penile shortening. J Sex Med. 2012;9:316-21.

21. Egydio PH, Kuehhas FE, Sansalone S. Penile length and girth restoration in severe Peyronie's disease using circular and longitudinal grafting. BJU Int. 2013;111(4 Pt B):E213-9.

22. Djordjevic ML, Kojovic V. Penile prosthesis implantation and tunica albuginea incision without grafting in the treatment of Peyronie's disease with erectile dysfunction. Asian J Androl. 2013;15:391-4.

23. Rolle L, Ceruti C, Timpano M, Sedigh O, Destefanis P, Galletto E, et al. A new, innovative, lengthening surgical procedure for Peyronie's disease by penile prosthesis implantation with double 
dorsal-ventral patch graft: the "sliding technique". J Sex Med. 2012;9:2389-95.

24. Rolle L, Falcone M, Ceruti C, Timpano M, Sedigh O, Ralph DJ, et al. prospective multicentric international study on the surgical outcomes and patients' satisfaction rates of the 'sliding' technique for end-stage Peyronie's disease with severe shortening of the penis and erectile dysfunction. BJU Int. 2016;117:814-20.

25. Egydio PH, Kuehhas FE. Penile lengthening and widening without grafting according to a modified 'sliding' technique. BJU Int. 2015;116:965-72.

26. Egydio PH, Kuehhas FE, Valenzuela RJ. Modified sliding technique $(\mathrm{MoST})$ for penile lengthening with insertion of inflatable penile prosthesis. J Sex Med. 2015;12:1100-4.

27. Wilson SK, Mora-Estaves C, Egydio P, Ralph D, Habous M, Love $\mathrm{C}$, et al. Glans necrosis following penile prosthesis implantation: prevention and treatment suggestions. Urology. 2017;107:144-8.

28. Egydio PH, Kuehhas FE. The multiple-slit technique (MUST) for penile length and girth restoration. J Sex Med. 2018;15:261-9.

29. Gaffney CD, Pagano MJ, Weinberg AC, Small AC, Kuehhas FE, Egydio $\mathrm{PH}$, et al. Lengthening strategies for Peyronie's disease. Transl Androl Urol. 2016;5:351-62.

30. Egydio PH. Enlargement of length and girth associated with implantation of penile prostheses. Implante de prótesis con reconstrucción y agrandamiento de pene en el mismo acto quirúrgico. Actas Urol Esp. 2020;44:333-9.

31. Egydio PH. A tunica expansion procedure (TEP): an innovative non-grafting proposal for penile enlargement (the Egydio TEP strategy). In: Russo G, Cocci A (eds). Peyronie's disease: pathophysiology and treatment. Academic Press: Elsevier Inc.; 2020. pp. 199-218.

32. Egydio PH. An innovative strategy for non-grafting penile enlargement: a novel paradigm for tunica expansion procedures. J Sex Med. 2020. https://doi.org/10.1016/j.jsxm.2020.05.010.

33. Vandeput JJ, Tanner JC, Boswick J. Implementation of parameters in the expansion ratio of mesh skin grafts. Plast Reconstructive Surg. 1997;100:653-6.
34. Henderson J, Arya R, Gillespie P. Skin graft meshing, overmeshing, and cross-meshing. Int J Surg. 2012;10:547-50.

35. Egydio PH, Taylor J, Taylor G, Goldstein I. PD25-01 engineering buckling force study for supporting that cylinder constriction and rear tip extender are associated with reduced axial rigidity - the implications on clinical practice. J Urol. 2017;197(4S):E502.

36. Eid JF, Wilson SK, Cleves M, Salem EA. Coated implants and "no touch" surgical technique decreases risk of infection in inflatable penile prosthesis implantation to $0.46 \%$. Urology. 2012;79:1310-5.

37. Weinberg AC, Pagano MJ, Deibert CM, Valenzuela RJ. Subcoronal inflatable penile prosthesis placement with modified notouch technique: a step-by-step approach with outcomes. J Sex Med. 2016;13:270-6.

38. Moncada I, Martínez-Salamanca JI, Jara J, Cabello R, Moralejo M, Hernández C. Inflatable penile prosthesis implantation without corporeal dilation: a cavernous tissue sparing technique. J Urol. 2010;183:1123-6.

39. Pagano MJ, Weinberg AC, Deibert CM, Hernandez K, Alukal J, Zhao L, et al. Penile intracavernosal pillars: lessons from anatomy and potential implications for penile prosthesis placement. Int $\mathbf{J}$ Impot Res. 2016;28:114-9.

40. Rosen RC, Riley A, Wagner G, Osterloh IH, Kirkpatrick J, Mishra A. The international index of erectile function (IIEF): a multidimensional scale for assessment of erectile dysfunction. Urology. 1997;49:822-30.

41. Althof SE, Corty EW, Levine SB, Levine F, Burnett AL, McVary $\mathrm{K}$, et al. EDITS: development of questionnaires for evaluating satisfaction with treatments for erectile dysfunction. Urology. 1999;53:793-9.

42. Broughton G, Janis JE, Attinger CE. The basic science of wound healing. Plast Reconst Surg. 2006;117(7 Suppl):12S-34S.

43. Janis JE, Harrison B. Wound healing: part I. Basic science. Plast Reconst Surg. 2014;133:199e-207e.

44. Wilson SK, Levine L, Wang R. "Make it as long as you can, Doc." Concomitant surgical treatments with penile implant to enhance penile size. Int J Impot Res. 2020. https://doi.org/10. 1038/s41443-020-0306-9. 